\title{
ANTÓNIO NÓVOA: REFLEXÕES SOBRE FORMAÇÃO CONTINUADA E A FORMAÇÃO A DISTÂNCIA
}

\author{
Entrevista com António Nóvoa \\ Universidade de Lisboa
}

O professor Dr. António Nóvoa, catedrático da Faculdade de Psicologia e de Ciências da Educação da Universidade de Lisboa, é mundialmente reconhecido pelas suas pesquisas acerca da formação de professores. Entre as suas obras de maior destaque encontram-se: "Profissão Professor"1 e "Vidas de Professores" ${ }^{2}$, publicadas na década de 1990. Nelas, o autor discute a importância das histórias de vida do professor e reconhece a ação educativa como fonte de saberes do trabalho profissional. Várias questões que permeiam o ofício docente são tratadas, como por exemplo, no que diz respeito a como os professores ensinam, quais conteúdos priorizam e por que alguns docentes são mais dedicados profissionalmente do que outros. As inferências apresentadas pelo autor culminam com a afirmativa de que a formação docente não se constitui de uma aglomeração de aptidões, habilidades e competências, mas evolui biograficamente, já que não há como separar o profissional da pessoa do professor. Noutras palavras, como preconiza Nóvoa, "o professor é a pessoa; e uma parte importante da pessoa é o professor ${ }^{3 n}$.

Em vista disso, em 22 de março de 2014, quando o professor Dr. António Nóvoa proferiu, a convite da Universidade Regional de Blumenau (FURB), a palestra de abertura do IV Encontro do Programa Institucional de Bolsa de Iniciação à Docência (PIBID), intitulada "A formação do professor na contemporaneidade: desafios e perspectivas" ${ }^{\prime 4}$, percebeu-se uma valiosa oportunidade para entrevistá-lo, acerca de alguns aspectos que tangem à formação docente, mais especificamente no que diz respeito à formação de professores na modalidade de ensino a distância e a formação continuada na profissão docente. Tais aspectos permeiam as pesquisas realizadas pelas entrevistadoras e culminarão nas dissertações de mestrado de duas delas.

\footnotetext{
${ }^{1}$ NÓVOA, António. Profissão professor. 2. ed. Porto: Porto Editora, 1999, 192 p.

${ }^{2}$ NÓVOA, António (Org.). Vidas de professores. Porto: Porto Editora, 1992, 214 p.

${ }^{3}$ Citação extraída da segunda edição da obra "Vidas de Professores" (NÓVOA, 1992, p.9).

${ }^{4} \mathrm{~A}$ palestra foi realizada no Teatro Carlos Gomes em Blumenau - SC.
} 
Entrevistadoras: Começamos agradecendo ao senhor pela disponibilidade em nos atender. Somos mestrandas no Programa de Pós-graduação em Educação da FURB e orientandas da professora Rita Buzzi Rausch aqui presente. Nossas pesquisas giram em torno dos saberes docentes e da formação continuada de professores. Então, por isso, o nosso interesse em conversar com o senhor sobre estes aspectos. Professor Nóvoa, em seus estudos o senhor tem discutido o pressuposto de que ainda não houve uma reflexão que permitisse transformar a prática em conhecimento, defendendo a ideia de que a formação de professores está muito afastada da profissão docente, das suas rotinas e culturas profissionais. A partir desta ideia, vamos fazer algumas perguntas que envolvem dois aspectos da formação docente: a formação inicial de professores a distância no Brasil e a formação continuada.

No que se refere à formação inicial de professores na modalidade de ensino a distância, entendemos ser de seu conhecimento que, no Brasil, segundo dados recentes do INEP, a partir de pesquisas feitas por Bernardete Gatti $(2011)^{5}$, formamse, atualmente, mais professores em cursos de Pedagogia na modalidade de Educação a Distância do que na modalidade presencial. De que modo o senhor percebe a repercussão, para o ensino em geral, desse crescente aumento de pedagogos formados a distância?

António Nóvoa: Eu julgo que é impossível. Quando se fala hoje na formação a distância há duas realidades diferentes. Uma realidade são os cursos totalmente a distância e, portanto, cursos que não têm nenhum momento presencial e que são realizados totalmente a distância. Eu pessoalmente acho impossível formar professores num curso destes. Acho que a formação de um professor implica momentos presenciais fortes. Não consigo conceber o que quer dizer formar um professor através de uma pedagogia, de um meio de educação totalmente a distância. Como, aliás, não consigo conceber o que seria formar um médico através de um curso totalmente a distância. Quer dizer, não consigo perceber o que isto quer dizer e, portanto, parece-me errado.

\footnotetext{
${ }^{5}$ GATTI, B. A.; BARRETTO, E. S. de S.; ANDRÉ, M. E. D. A. Políticas docentes no Brasil: um estado da arte. Brasília: UNESCO, 2011. 300 p.
} 
Outra coisa totalmente diferente dessa é a utilização, nos cursos de formação de professores, de estratégias de E-learning, ou de B-learning ${ }^{6}$. Estas estratégias muitas vezes são muito úteis. Nós fizemos uma avaliação de alguns cursos de $E$ learning na Universidade de Lisboa que foram fomentados durante meu mandato como reitor, e a primeira avaliação desses cursos, parece paradoxal, era a primeira qualidade que estes cursos tinham: criavam uma maior proximidade entre 0 professor e o aluno. Parece estranho porque estes são a distância.

Mas, o que é fato é que as redes, a utilização das redes sociais, de grupos de encontro, de grupos de reflexão online, eu acho que tem um potencial, do ponto de vista da formação de um professor, enorme. Permitem interações, permitem discussões, permitem reflexões. Agora, isto é uma parte do curso. Um curso totalmente a distância para formar um professor, eu não consigo perceber o que é.

Entrevistadoras: Ok! Iríamos perguntar se o senhor considera que a formação a distância possibilita transformar a prática docente em conhecimento, mas isto já está respondido, não é?!

António Nóvoa: Está respondido. Isto me parece, eu insisto nesse ponto, eu acho que, por exemplo, algumas das experiências mais interessantes em que eu participei, inclusive até anterior à existência das redes sociais, ainda havia apenas o e-mail, mas não havia hipótese de interação nenhuma, foi, por exemplo, constituirmos comunidades de escrita dos professores. Éramos vários professores e cada um ia escrevendo sobre a sua prática e enviava um e-mail, os outros reagiam e etc. E este trabalho de produção, de reflexão, através das redes sociais, hoje em dia é muito facilitado pelo skype, pelas redes sociais e etc. Acho que é de uma enorme utilidade para construir conhecimento, agora na formação inicial de um professor, eu não vejo como isto pode ser realizado sem um trabalho presencial.

Entrevistadoras: E como vem acontecendo o processo de formação inicial para a docência em Portugal em relação a estas duas modalidades de ensino? Como é lá professor?

\footnotetext{
${ }^{6}$ E-learning e B-learning são formas de estudo a distância viabilizadas pela internet. A diferença está apenas no fato de que o E-learnig realiza-se totalmente a distância por meio de mídias eletrônicas ao passo que o $B$-learning requer momentos presenciais.
} 
António Nóvoa: Eu acho que, de um modo geral, no mundo, acho que há muitos poucos programas de formação de professores a distância. Pode haver alguns na área de formação continuada, agora formação inicial de professores a distância, acho que são praticamente inexistentes.

Que eu saiba, em Portugal há uma iniciativa importante que é a Universidade Aberta de Portugal e que tem um trabalho importante na área de formação de professores, mas que complementa partes a distância com partes presenciais e que é, sobretudo, para uma atualização dos professores e não para uma formação inicial.

Entrevistadoras: Perfeito.

António Nóvoa: Internacionalmente.

Entrevistadoras: É uma moda brasileira!

António Nóvoa: É. Foi uma moda brasileira.

Entrevistadoras: Professor, sobre a formação continuada, no Brasil há indicadores oriundos de pesquisas, como uma realizada, em parceria pelas professoras Bernardete Gatti e Elba Siqueira de Sá Barreto ${ }^{7}$, que indicam um forte investimento na formação continuada de professores. A produção teórica e empírica destaca que há avanços a considerar, porém, não se percebem ainda na prática reflexos efetivos de que a formação continuada de fato esteja contribuindo para a melhoria da qualidade da educação. Então perguntamos: quais proposições o senhor sugere para que a formação continuada de professores repercuta na prática pedagógica?

António Nóvoa: O grande problema da formação continuada foi que historicamente ela foi organizada fora das escolas, porque as escolas não tinham condições. O que é verdade, porque não havia tempo das escolas, porque os horários dos professores não permitiam. Então foi organizada em centros de formação ou em universidades ou em institutos fora do trabalho escolar e na verdade esse tipo de formação, as repercussões na prática pedagógica são muito limitadas, não é? Porque a pessoa faz uma formação num determinado ambiente e depois é muito difícil transferir aquela formação que fez para o ambiente da escola.

\footnotetext{
${ }^{7}$ GATTI, B. A.; BARRETO, E. S. de S. Professores do Brasil: impasses e desafios. Brasília: UNESCO, 2009, 294 p.
} 
É muito difícil e, portanto, a nossa tendência hoje é que toda formação continuada deve estar preferentemente dentro das escolas. Então, tem que se reorganizar as escolas de uma determinada maneira. Acho que a maneira que organizamos hoje, tanto o tempo escolar como o espaço escolar são coisas completamente obsoletas. Quer dizer, nós temos que ter, e acho que a ideia de sala de aula é uma maneira que vai acabar daqui a pouco tempo. Quer dizer, as salas de aula, nós vamos ter que por abaixo as paredes todas e alterar a configuração das escolas, e o tempo é a mesma coisa. Essa ideia de tempo, de uma hora, de fatia de um tempo, quer dizer, nada disso corresponde ao que são hoje as sociedades do século XXI.

$\mathrm{E}$ eu acho que nós precisamos ter uma escola onde seja natural que os tempos estejam organizados de outra maneira, onde seja natural que, de repente, metade dos alunos esteja a estudar sozinhos, mas onde seja natural também que na mesma turma possam estar dois professores ou três professores ao mesmo tempo e que tudo isso possa contribuir para instaurar dinâmicas de conhecimento da realidade, dinâmicas de partilha e dinâmicas de reflexão dentro das escolas e deve ser num certo sentido a partir destas dinâmicas que se deve buscar o conhecimento exterior. $\mathrm{Eu}$, por exemplo, sou contra um professor fazer, vamos imaginar um curso, que é um curso extraordinariamente importante, sobre o problema da violência nas escolas. Então vamos fazer um curso sobre a violência nas escolas para a formação continuada. A violência nas escolas é um tema extraordinariamente importante, muito conhecimento importante sobre isso. Ir a universidade fazer um curso sobre isso serve muito pouco, quer dizer, não adianta muito. Mas, por exemplo, se no interior da escola nós detectarmos dificuldades sobre questões de violência, a partir de um diagnóstico feito dentro das escolas pelos próprios professores e formos até a universidade e pedir que venham cá trabalhar conosco esse tema, venham cá os sociólogos, venham cá os psicólogos, trabalhar conosco este tema, mas a partir da nossa realidade. Isto é extraordinariamente importante, para dizer que o contributo de fora pode ser um contributo importante, mas contributo de fora tem que ser organizado a partir de uma preocupação de dentro e não uma preocupação de fora. Ora, o que acontece na formação continuada é que muitas vezes cursos são oferecidos a partir do interesse dos professores universitários. Ah, eu sei falar de história da educação, então oferece um curso de história da educação, isto não é 
formação continuada. Agora, um professor ou professores ser levado na escola, para trabalhar com eles determinadas realidades, isso com certeza é muito importante. Essa mudança ainda não se fez em muitas partes do mundo, não é só no Brasil, é uma mudança de concepção que ainda não se fez. Eu, por exemplo, quando se inseriram as primeiras legislações sobre a formação de professores em Portugal, em 1991, os professores eram obrigados a fazer os cursos, eles detestavam. Quer dizer, o professor tem a vida horrível de tempo, e no mais, naquele tempo tem que andar quilômetros para fazer um curso que não o interessa para nada. Os professores reagiram muito a isso e eu, em três escolas, instaurei ciclos de debates com os professores, que aconteciam na sexta-feira. Eu estava lá com eles refletindo aquilo, nunca contava para nada no ponto de vista de crédito, mas os professores estavam todos lá, porque aquilo fazia diferença para eles. Eu perguntei uma vez para os ministros: mas por que os ciclos não vão contar como formação continuada também? E lá eles instauraram que estes ciclos também poderiam contar como formação continuada e assim começou a se inverter algumas lógicas.

Eu creio que se nós não fizermos isso, a formação continuada vai continuar sendo um mercado, isso alimenta um mercado, alimenta um negócio, negócios de universidades, negócios de empresas, negócios de cursos, mas utilidade, por mais interessantes que os cursos sejam, os cursos podem ser notavelmente interessantes, mas a consequência sobre o trabalho profissional vai ser muito, muito, muito limitada, não é?

Entrevistadoras: Seriam estas as nossas perguntas. Para finalizar, gostaríamos que o senhor deixasse uma mensagem norteadora aos professores do Brasil.

António Nóvoa: A mensagem mais importante que se pode deixar para os professores de todo o lado é a necessidade de construir uma identidade como profissionais, que já tiveram no passado, mas que foram perdendo. Eu acho que a profissão está muito fragmentada, há uma fragmentação muito grande na profissão não é? Fragmentação para o Ensino Médio, para Educação Infantil, a fragmentação é muito grande.

É preciso reconstruir certa identidade do ser professor, porque é a partir da reconstrução dessa identidade que se podem conceber novas dinâmicas de 
formação, pode-se conceber todo um conjunto de novas coisas. No coração dessa identidade está um problema muito difícil para os professores, é que as pessoas têm uma cultura muito individualista e se nós não cortarmos com essa cultura individualista, nós teremos dificuldades. Somos a profissão mais individualista da sociedade do século XXI. Se repararem hoje, os advogados trabalham em grandes empresas, os médicos trabalham com a equipe, nenhum médico trabalha sozinho, os engenheiros, quer dizer, fazer uma obra hoje obriga a ter 30 profissões diferentes, trabalhar em conjunto à volta de uma mesa.

Os professores continuam com a ilusão que podem trabalhar sozinhos. Se não cortarem com essa cultura individualista, que foi construída por muitas razões, até pela maneira como as escolas conceberam os espaços de salas de aula fechados etc. Se não cortarem com essa cultura individualista, é difícil construir essa identidade e um espaço mais rico na profissão.

Creio que esse é o grande desafio. Claro que depois há muitas outras coisas, há os salários, há a desvalorização profissional, as condições das escolas, há lutas que são políticas também sobre essas matérias, mas elas devem ter como coração este reconstruir de identidade, de uma identidade coletiva dos professores.

\section{Entrevistado:}

\section{ANTÓNIO NÓVOA}

Graduado em Ciências da Educação pela Universidade de Lisboa (1976). Mestre em Ciências da Educação pela Université de Geneve (1982). Doutor em Ciências da Educação pela Université de Geneve (1986). Professor titular da Universidade de Lisboa.

\section{Entrevistadoras:}

ANA PAULA OLIVEIRA ITEN

anapaulaiten@gmail.com

FURB - Fundação Universidade Regional de Blumenau

\section{OSMARINA BLOCK}

osmarina.block@gmail.com

FURB - Fundação Universidade Regional de Blumenau

\section{RITA BUZZI RAUSCH}


Atos de Pesquisa em Educação - ISSN 1809-0354

Blumenau, v. 10, n.2, p.561-567, mai./ago. 2015

DOI: http://dx.doi.org/10.7867/1809-0354.2015v10n2p561-567

ritabuzzirausch@gmail.com

FURB - Fundação Universidade Regional de Blumenau 